\title{
Corrigendum: Successful surgical missions for cleft
}

\author{
Young-Wook Park, D.D.S., M.S.D., Ph.D. \\ Department of Oral and Maxillofacial Surgery, College of Dentistry, Gangneung-Wonju National University, Gangneung, Korea
}

J Korean Assoc Oral Maxillofac Surg 2018;44:249-250。 https://doi.org/10.5125/jkaoms.2018.44.6.249

This correction is being published to correct mistakenly grouping the organization Smile Train under the umbrella of non-governmental, mission-based organizations. In fact, Smile Train empowers local medical professionals to provide care within their own communities in response to the limitations of the mission model.

The author apologizes for any inconvenience this may have caused.

\section{Before correction}

Fortunately, humanitarian surgical missions for patients with CLP in developing countries have a long history. Non-governmental, mission-based organizations such as Smile Train, Operation Smile, and Interplast $\ldots . . .$.

\section{After correction}

Fortunately, humanitarian surgical missions for patients with CLP in developing countries have a long history. Non-governmental, mission-based organizations such as Operation Smile and Interplast $\cdots . . .$.

(c) This is an open-access article distributed under the terms of the Creative Commons Attribution Non-Commercial License (http://creativecommons.org/licenses/by-nc/4.0/), which permits unrestricted non-commercial use, distribution, and reproduction in any medium, provided the original work is properly cited.

Copyright (C) 2019 The Korean Association of Oral and Maxillofacial Surgeons. All rights reserved. 